\title{
Perancangan ID Fan dan Cerobong pada Unit Pembangkit Listrik Tenaga Sampah
}

\section{ID Fan and Chimney Design on Waste to Energy Power Plant}

\author{
WAHYU PURWANTA DAN FEDDY SURYANTO \\ Pusat Teknologi Lingkungan (PTL), Badan Pengkajian dan Penerapan Teknologi (BPPT) \\ wahyu.purwanta@bppt.go.id
}

\begin{abstract}
The problem for big cities in implementing the MSW disposal method is the land availability. Hierarchically, a suitable method for solving this condition is not to dispose the MSW into the landfill but to treat it in the thermal processing, such as incineration. The bonus of this incineration is the heat dissipation that can be utilized to generate electricity. Burning MSW through incinerator that converts into energy is often called a Waste to Energy (WtE) or PLTSa. Beside the benefit of the high temperature flue gas that can produce electricity, PLTSa also emits major pollutants in the flue gas such as particulates, $\mathrm{SO}_{2}, \mathrm{NOx}, \mathrm{CO}, \mathrm{HCl}$, dioxins and furans. In order to meet the emission standards, the PLTSa design has to be equipped with APCD's such as cyclone, semi-dry scrubber and bag filter. ID fan withdraws the flue gas into the chimney before discharging it into the ambient air through the top exit of chimney. The main parameters in the design of the ID fan and chimney are the quantity, quality and temperature of the flue gas as well as the environmental parameters, such as air temperature, atmospheric stability, wind speed and direction. The design of the chimney was carried out with a technical calculation approach, simulation of Gaussian dispersion model and the compliance of related regulations from the MoEF. In the design of PLTSa with a waste capacity of 350 tons/day, specification of the stack is $2.02 \mathrm{~m}$ diameter and the $70 \mathrm{~m}$ height whereas ID fan is $70,000 \mathrm{cfm}$ flue gas flowrate, 400 BHP power, 80\% mechanical efficiency and 25 inch $\mathrm{H}_{2} \mathrm{O}$ pressure pump.
\end{abstract}

Keywords: Waste-to-energy, flue gas, ID fan, chimney

\begin{abstract}
ABSTRAK
Salah satu masalah bagi kota-kota besar dalam menerapkan metode pengolahan sampah adalah ketersediaan lahan. Secara hierarkis metode yang mampu memenuhi kondisi ini adalah pengolahan dengan metode termal sekaligus memanfaatkan buangan panas yang ada untuk membangkitkan energi listrik. Pembakaran sampah dengan insinerator yang merubah sampah menjadi energi ini sering juga disebut Pembangkit Listrik Tenaga Sampah (PLTSa). Salah satu hasil samping PLTSa adalah flue gas yang temperaturnya tinggi serta mengandung polutan utama seperti partikulat, $\mathrm{SO}_{2}, \mathrm{NO}_{x}$ dan $\mathrm{CO}$. Agar memenuhi baku mutu emisi, rancangan PLTSa dalam studi ini dilengkapi dengan unit cyclone, semi dry scrubber, bag filter dan ID fan serta cerobong sebagai unit pembuangan akhir flue gas. Sebagai unit akhir pembuang flue gas ke lingkungan, peran cerobong sangat penting sehingga perlu beberapa pendekatan dalam perancangan. Parameter desain utama dalam perancangan cerobong adalah kuantitas, kualitas dan suhu dari flue gas serta parameter meterologis lingkungan seperti suhu udara, stabilitas atmosfer, kecepatan dan arah angin. Dalam perancangan cerobong pada studi ini dilakukan dengan pendekatan perhtiungan teknis, simulasi model dispersi Gaussian serta peraturan terkait dari Kementerian Lingkungan Hidup dan Kehutanan. Dalam rancangan PLTSa dengan kapasitas olah sampah 350 ton/hari ditetapkan diameter cerobong 2,05 m dengan tinggi $70 \mathrm{~m}$, serta diperlukan ID fan sebagai pendorong flue gas dengan spesifikasi $\mathrm{Q}=70.000 \mathrm{cfm}, \mathrm{BHP}=400$, mechanical efficiency $80 \%$ dan static pressure pompa $=25$ inch $\mathrm{H}_{2} \mathrm{O}$.
\end{abstract}

Kata kunci: Sampah menjadi energi, gas buang, ID fan, cerobong 


\section{PENDAHULUAN}

\subsection{Latar Belakang}

Salah satu masalah lingkungan yang masih menjadi persoalan di kota-kota di Indonesia adalah sampah kota. Aktivitas perkotaan menghasilkan sampah yang jika tidak dikelola secara benar akan berdampak pada lingkungan seperti pencemaran tanah dan perairan oleh lindi maupun pencemaran udara oleh gas rumah kaca dan gas-gas berbahaya lainnya. Pengelolaan sampah di Indonesia mengacu kepada Undang Undang No.18 tahun 2008 tentang pengelolaan sampah, dimana metode pengolahan sampah terdapat beberapa pilihan yang secara umum dikenal dengan sistem pengelolaan sampah terpadu ${ }^{(1)}$.

Pilihan ini membentuk suatu piramida hierarki mulai dari yang paling disukai untuk diterapkan (di puncak) serta yang paling tidak disukai di dasar piramida. Ukuran bangun piramida juga menunjukkan besarnya sampah yang dikelola dengan metode tersebut(2). Porsi sampah yang dikelola melalui pencegahan (prevention), pengurangan (reduction), guna ulang (reuse) dan daur ulang (recycle) saat ini relatif masih sedikit, di bawah $2 \%$ dari total sampah yang dikelola di Indonesia.

Dalam prakteknya hierarki tersebut tidak perlu dilaksananakan secara kaku. Suatu metode penanganan sampah dapat dilaksanakan terlebih dahulu tanpa menunggu metode level sebelumnya terlaksana. Dalam banyak kasus termasuk Indonesia, opsi pembuangan ke TPA (final disposal) dipilih terlebih dahulu dan diusahakan melayani semua jumlah sampah yang ada, dan bilamana kondisinya memungkinkan (khususnya biaya) digantikan oleh hierarki di atasnya, dengan demikian tidak ada bagian sampah yang tidak terkelola(1,2).

Bagi kota metropolitan maupun kota besar masalah metode pengolahan sampah juga menjadi problem tersendiri khususnya terkait semakin sulitnya mendapatkan lahan. Secara hierarkis metode yang mampu memenuhi kondisi ini adalah pengolahan dengan metode termal sekaligus memanfaatkan buangan panas yang ada untuk membangkitkan energi listrik yang dikenal dengan waste-to-energy (WtE). Pemanfaatan panas gas buang atau recovery ini akan melengkapi konsep 3R menjadi 4R (3R+Recovery) yang saat ini juga banyak diterapkan di kota-kota besar dunia yang kemudian dikenal dengan Pembangkit Listrik Tenaga Sampah (PLTSa) ${ }^{(1)}$. Selain memanfaatkan panas gas buang (flue gas) untuk membangkitkan listrik, sisa gas buang suatu PLTSa harus memenuhi baku mutu yang ditetapkan sehingga perlu diolah terlebih dahulu dengan alat pengendalian pencemaran udara seperti cyclone, scrubber dan bag filter sebelum dibuang melalui cerobong (chimney) ke udara bebas.

Walau cerobong berada pada posisi akhir suatu unit alat pengolahan (treatment) gas buang namun memegang peranan penting dalam mentransportasikan dan mendispersikan gas buang ke atmosfer. Setiap negara memiliki regulasi dalam dimensi cerobong. Tulisan ini memaparkan hasil perhitungan dan perancangan ID fan dan cerobong suatu unit pengolah sampah proses termal khususnya tipe stoker grate insinerator dengan kapasitas 350 ton/hari yang selanjutnya disebut secara singkat sebagai PLTSa.

\subsection{Tujuan Penelitian}

Perancangan suatu ID fan dan cerobong memerlukan perhitungan sejak tahap awal proses pembakaran sampah khususnya dalam menentukan kehilangan tekanan (pressure losses) dan laju volume gas buang. Selanjutnya dengan dimensi yang dipilih akan diuji dengan model dispersi Gaussian serta kesesuaiannya dengan peraturan yang ada.

\section{BAHAN DAN METODE}

Perancangan ID fan didasarkan pada perhitungan matematis dengan data utama adalah laju volume gas buang yang dihasilkan, kehilangan tekanan aliran gas buang dalam peralatan dan ducting serta kebutuhan tekanan kerja dari gas buang. Sedangkan penentuan dimensi cerobong mempertimbangkan hasil perhitungan matematis, pemodelan dengan dispersi Gaussian serta peraturan yang berlaku di Indonesia. Perhitungan dimensi secara matematis memerlukan variabel laju volume dan kecepatan aliran gas buang, suhu dan tekanan gas buang. Adapun pemodelan dispersi Gaussian dilakukan terhadap partikulat dengan variabel meteorologi daerah Tangerang Selatan.

\section{HASIL DAN PEMBAHASAN}

\subsection{Insinerator Pembangkit Listrik}

\section{Sistem Pembakaran dan Konversi Energi}

Teknologi yang digunakan dalam pembakaran sampah untuk menghasilkan panas dipilih insinerator jenis stoker reciprocating grate dan termasuk dalam kelompok proses termal. Tujuan utama penggunaan insinerator adalah untuk memusnahkan sampah secara cepat dalam suhu tinggi baik untuk limbah padat, sludge maupun limbah cair yang sulit terdegradasi. Kemampuan 
insinerator dalam mereduksi sampah sekitar $80 \%$ volume atau $90 \%$ beratnya menjadi kelebihan metode termal ini(3). Salah satu alternatif memusnahkan sampah perkotaan adalah dengan insinerator skala kota. Metode insinerasi skala kota telah berkembang dengan memanfaatkan panas yang ditimbulkan sebagai energi yang dikonversikan menjadi energi listrik sehingga dikenal sebagai Waste-to-Energy (WtE). Di Indonesia WtE dikenal sebagai pembangkit listrik tenaga sampah (PLTSa). Komponen-komponen utama dalam PLTSa antara lain; (1) bunker sampah (pit storage), (2) tungku bakar, (3) sistem boiler dan unit konversi energi, (4) sistem pengendalian gas buang ${ }^{(4)}$. Diagram alir proses dalam PLTSa kapasitas 350 ton/hari ditampilkan dalam Gambar 1. Dalam studi ini plant PLTSa direncanakan berlokasi di TPA Cipeucang, Kota Tangerang Selatan.

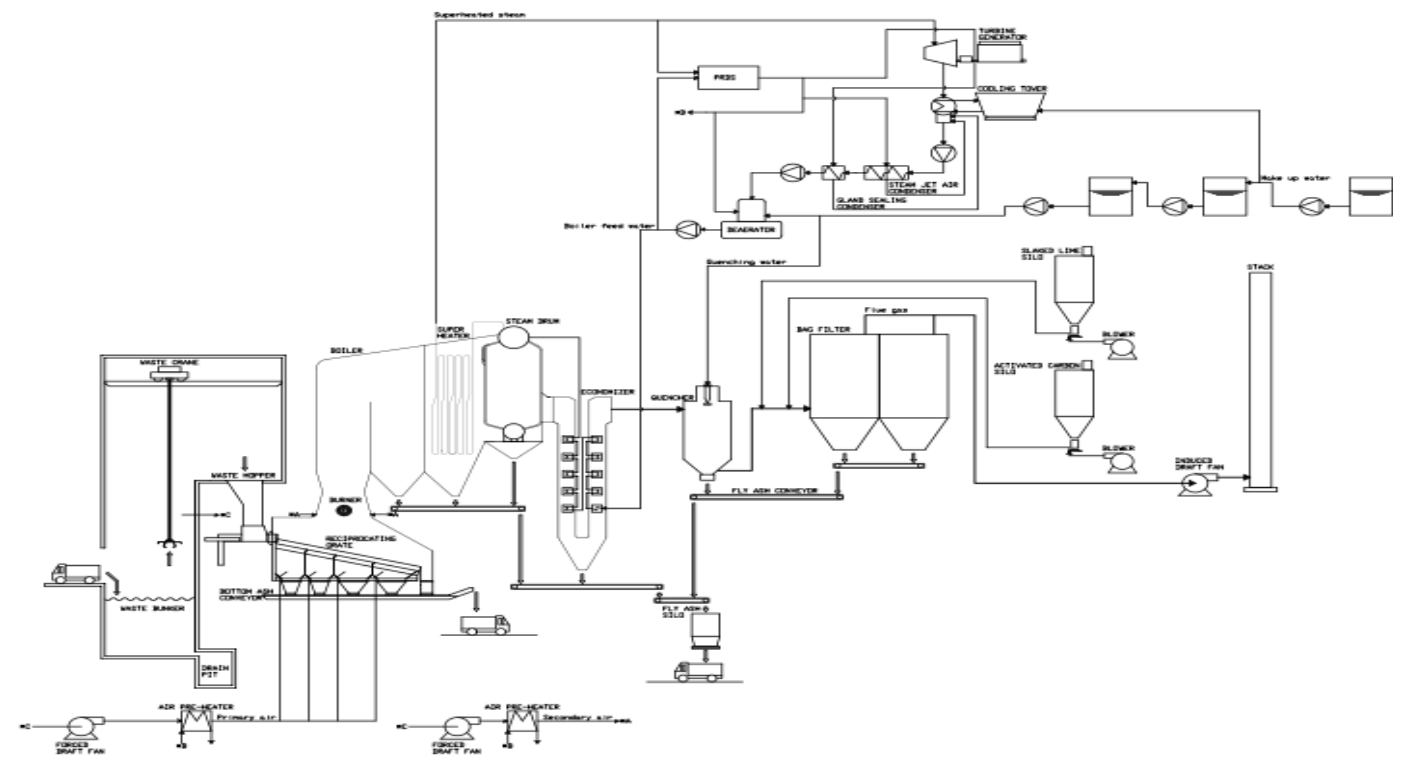

Gambar 1. Diagram alir proses PLTSa kapasitas 350 ton/hari

Suatu bunker penampungan didesain untuk menampung $2-3$ hari, namun untuk kondisi ketidakpastian akibat gangguan dalam transportasi sampah yang sering terjadi seperti di Indonesia disarankan untuk didesain $3-5$ hari(5). Dalam rancangan ini, densitas sampah ditetapkan 0,350 ton $/ \mathrm{m}^{3}$, serta cadangan sampah untuk 3 hari, sehingga kapasitas bunker sebesar $3000 \mathrm{~m}^{3}$. Ruang penyimpanan sampah dilengkapi feed crane yang berfungsi mengaduk dan mengangkut sampah untuk dibawa ke ruang umpan insinerator (charging hopper). Tingginya kandungan sampah organik dan kandungan airnya yang sekitar $50 \%$ membuat ruang penyimpanan akan menghasilkan lindi yang harus dikelola(6).

Tungku bakar (furnace) sebagai komponen utama dalam metode termal umumnya dilengkapi dengan sistem penghantar sampahnya (grate) dan pengapian (hearth). Grate berfungsi untuk mendorong dan membalikkan sampah agar terjadi pembakaran sempurna. Jenis grate dalam rancangan ini adalah reciprocating grate atau gerakan ganda. Sistem tungku ini memungkinkan sampah yang masuk sambil bergerak akan dikeringkan kemudian dibakar secara sempurna dengan pasokan udara dari bawah grate ${ }^{(7)}$. Untuk tetap mempertahankan terjadinya proses pembakaran, perlu ada pasokan oksigen ke tungku. Sistem konversi energi panas gas buang menjadi energi listrik dilakukan melalui perantara steam boiler untuk menggerakkan turbin pembangkit. Pembakaran 350 ton sampah per hari (kapasitas rancangan) dengan nilai kalor (LHV) sebesar $1300 \mathrm{kkal} / \mathrm{kg}$ diperkirakan akan menghasilkan $5 \mathrm{MW}$ listrik. Beberapa parameter desain dasar PLTSa dtampilkan pada Tabel 1.

Tabel 1. Ringkasan simulasi desain PLTSa(1)

\begin{tabular}{lc}
\hline \multicolumn{1}{c}{ Parameter } & Nilai \\
\hline Steam generated, $\mathrm{kg} / \mathrm{jam}$ & 28.954 \\
Steam pressure, bar & 13 \\
Excess air, \% & 80 \\
Boiler efficiency & 78 \\
FGR, \% & 20 \\
LHV sampah, $\mathrm{kkal} / \mathrm{kg}$ & 1.300 \\
Boiler heat load, $\mathrm{kW}$ & 4.450 \\
\hline
\end{tabular}




\section{Pengendalian Polutan Gas Buang}

Salah satu sisa proses dari PLTSa selain listrik adalah dihasilkannya gas buang sisa pembakaran ke lingkungan. Dalam perancangan alat pengendalian gas buang insinerator sangat penting dengan keberadaan data kualitas serta kuantitas gas buang itu sendiri. Perancangan plant kapasitas 350 ton/hari ini menggunakan asumsi bahwa kandungan gas buang secara umum akan mengandung partikulat, gas asam, logam berat, $\mathrm{NOx}, \mathrm{CO}_{2}, \mathrm{SO}_{2}$, dan dioksin/ furans( ${ }^{(8)}$. Berbagai polutan dalam gas buang inilah yang harus direduksi melalui serangkaian alat pengendali polutan agar memenuhi baku mutu emisi (BME) sesuai Peraturan Menteri Lingkungan Hidup Dan Kehutanan no.70 tahun 2016 tentang Baku Mutu Emisi Usaha dan/atau Kegiatan Pengolahan Sampah Secara Termal. Berdasarkan material polutan yang ingin dihilangkan, maka peralatan yang akan dirancang antara lain ${ }^{(9)}$;

a. Partikulat, dapat direduksi dengan cyclone atau multi-cyclone namun alat ini menjadi tidak efektif untuk mengurangi partikulat di bawah 5 microns.

b. Gas asam dapat dinetralkan dengan wet scrubber yang menyemprotkan larutan kapur serta dilengkapi dengan penangkapan merkuri $(\mathrm{Hg})$ sehingga berfungsi sebagai absorber, proses ini dikenal sebagai de-SOx. Sedangkan merkuri bisa dijerab lewat carbon injection yang juga bisa mengontrol dioksin.

c. Gas NOx, umumnya disisihkan dengan SNCR (selective-non catalytic reduction). SNCR mengkonversi NOx menjadi Nitrogen yang lebih tidak berbahaya dengan menghembuskan ammonia atau urea ke tungku panas. Peralatan de-NOx ini tidak termasuk dalam rencana rancangan.

d. Gas $\mathrm{CO}_{2}$, dilakukan penyisihan dengan proses absorpsi alkaline dan sejauh ini yang tergolong sukses adalah amine-solvent.

e. Gas $\mathrm{SO}_{2}$, umumnya disisihkan dengan proses desulfurisasi dengan limestone-gypsum.

f. Dioksin, umumnya bersumber pada pembakaran sampah yang tidak terkontrol, akibat kegagalan insinerator mempertahankan suhu tinggi. Akan tetapi dioksin juga bisa terbentuk ketika gas melewati APCD yang dikenal de novo process Pada WtE incinerator yang bekerja pada suhu $850^{\circ} \mathrm{C}$ (sangat dianjurkan $1000^{\circ} \mathrm{C}$ ) atau lebih dapat mencegah munculnya dioksin.

Dalam upaya memenuhi kriteria BME yang berlaku, maka unit awal yang harus ada adalah cyclone untuk menyisihkan $98 \%$ partikulat ukuran
$>5$ microns serta secara rutin dapat menyisihkan $90 \%$ partikulat ukuran $15-20$ microns $^{(10)}$. Cyclone belum bisa menurunkan kadar partikulat dalam BME, oleh karena itu harus disertai baghouse filter yang mampu menyisihkan partikulat hingga ukuran 0,3 microns. Pembakaran sampah kota akan menghasilkan emisi $\mathrm{SO}_{2}$ yang berbahaya ke lingkungan. Penyisihan $\mathrm{SO}_{2}$ akan dilakukan dengan sistem basah dengan menyemprotkan bahan kimia lainnya. Dalam perancangan ini dibuat tanki dengan penyemprotan $\mathrm{Ca}(\mathrm{OH})_{2}$ dan karbon aktif (sebagai adsorben). Penggunaan karbon aktif akan turut mereduksi gas-gas dalam konsentrasi rendah seperti VOCs. Sebelum flue gas dibuang melalui cerobong akan dirancang suatu bagfilter dan wet scrubber. Serangkaian alat pengendali polutan gas buang (Air Pollution Control Devices/APCD) dalam rancangan ini meliputi cyclone, semi dry scrubber, bag filter serta chimney (cerobong). Desain APCD tersebut meliputi penentuan dimensi alat, kapasitas penyisihan (removal efficiency), material serta harga pressure loss yang terjadi di dalam pengaliran gas buang melalui alat tersebut. Pressure losses keseluruhan dari peralatan dalam plant akan menentukan desain ID fan dan juga cerobong ${ }^{(11)}$.

\section{Perhitungan Laju Volume Gas Buang dan Pressure Losses}

Jumlah dan komposisi gas buang yang dihasilkan dari pembakaran sampah akan bergantung kepada jumlah sampah yang dibakar serta komposisi sampahnya itu sendiri. Dalam perancangan ini digunakan data komposisi dan karakteristik sampah Kota Tangerang Selatan yang bersumber dari kawasan perumahan dan nonperumahan serta pada dua musim baik penghujan dan kemarau (12). Secara stoikiometrik, pembakaran sampah akan menghasilkan hasil reaksi sebagai berikut(13).

$$
C_{n} H_{m}+\left(n+\frac{m}{4}\right)\left(O_{2}+3,78 N_{2}\right) \stackrel{\text { yields }}{\longrightarrow} n \mathrm{CO}_{2}+\frac{m}{2} \mathrm{H}_{2} \mathrm{O}+3,78\left(n+\frac{m}{4}\right) N_{2}
$$

Melalui perhitungan stoikiometri dengan memperhatikan mol reaktan dan hasil reaksi pembakaran maka diperoleh hasil kebutuhan udara untuk pembakaran sebesar $72.089 \mathrm{~kg} / \mathrm{jam}$ serta menghasilkan gas buang sebesar $84.723 \mathrm{~kg} / \mathrm{jam}$, dimana laju volume gas buang merupakan fungsi suhu dan densitasnya. Data dan hasil perhitungan ditampilkan pada Tabel 2. 
Tabel 2. Laju volume gas buang dan sumbernya

Kebutuhan udara bakar dan laju gas buang

\begin{tabular}{ll}
\hline Laju sampah (fuel) & $14.583 \mathrm{~kg} / \mathrm{jam}$ \\
\hline Laju udara (inlet) & $72.089 \mathrm{~kg} / \mathrm{jam}$ \\
\hline Laju gas buang & $84.723 \mathrm{~kg} / \mathrm{jam}$ \\
\hline
\end{tabular}

Suhu, densitas dan sumber gas buang

\begin{tabular}{lll}
\hline$\rho$ gas buang $\left(900^{\circ} \mathrm{C}\right)$ & $0,3010 \mathrm{~kg} / \mathrm{m}^{3}$ & Boiler \\
\hline$\rho$ gas buang $\left(220^{\circ} \mathrm{C}\right)$ & $0,7218 \mathrm{~kg} / \mathrm{m}^{3}$ & Cyclone \\
\hline$\rho$ gas buang $\left(200^{\circ} \mathrm{C}\right)$ & $0,7480 \mathrm{~kg} / \mathrm{m}^{3}$ & Scrubber \\
\hline$\rho$ gas buang $\left(160^{\circ} \mathrm{C}\right)$ & $0,8288 \mathrm{~kg} / \mathrm{m}^{3}$ & Bag filter \\
\hline$\rho$ gas buang $\left(150^{\circ} \mathrm{C}\right)$ & $0,8490 \mathrm{~kg} / \mathrm{m}^{3}$ & Cerobong \\
\hline
\end{tabular}

Hasil perhitungan laju volume gas buang digunakan untuk perancangan unit APCD dengan mempertimbangkan suhu di titik inlet setiap APCD yang akan mempengaruhi kuantitas gas buang yang diolah, hal ini mengingat densitas gas akan sangat mempengaruhi laju volume gas buang. Dengan laju volume gas buang sebesar 84.723 $\mathrm{kg} / \mathrm{jam}$, bila mempertimbangkan kemungkinan adanya tambahan volume akibat treatment dalam bentuk udara tambahan, maka margin desain ditambahkan $15 \%$ sehingga kapasitas ID fan dalam rancangan ini diperoleh sebesar $120.286 \mathrm{~kg} / \mathrm{jam}$ $(70.797 \mathrm{cfm})$. Hasil perhitungan kehilangan tekanan dari tiap alat serta sepanjang duct ditampilkan dalam Tabel 2 dan Tabel 3.

Tabel 3. Perhitungan pressure losses pada alat

\begin{tabular}{lll}
\multirow{2}{*}{ Unit } & \multicolumn{2}{c}{ Pressure drop (inch. $\mathrm{H}_{2} \mathrm{O}$ ) } \\
\cline { 2 - 3 } & \multicolumn{1}{c}{ Teoritis } & Rancangan \\
\hline Boiler/HE & $10-15^{(7)}$ & 12 \\
\hline Cyclone & $1-16^{(9)}$ & 1,17 \\
\hline Semi Dry Scrubber & $1-4^{(9)}$ & 2,00 \\
\hline Bag filter & $5-10^{(14)}$ & 3,17 \\
\hline $\begin{array}{l}\text { Duct work + minor } \\
\text { losses }\end{array}$ & - & $\left.0,01^{*}\right)$ \\
\hline Static pressure & 1,1 & $\left.1,10^{* *}\right)$ \\
\hline Total & & 19,45 \\
\hline $\begin{array}{l}\text { ") Lihat Tabel } 3 \\
* *\end{array}$ &
\end{tabular}

Tabel 4. Friction losses dalam ductwork

\begin{tabular}{lcccc}
\hline \multicolumn{1}{c}{ Segmen } & $\begin{array}{c}\mathrm{Q} \\
(\mathrm{cfm})\end{array}$ & $\begin{array}{c}\text { Panjang } \\
(\mathrm{m})\end{array}$ & $\begin{array}{c}\text { Dia. } \\
\text { (in.) }\end{array}$ & $\begin{array}{c}\text { Friction } \\
\text { loss } \\
(\mathrm{in.H})\end{array}$ \\
\hline $\begin{array}{l}\text { Boiler- } \\
\text { Cyclone }\end{array}$ & 69.085 & 10 & 12 & 0,00095 \\
\hline $\begin{array}{l}\text { Cyclone- } \\
\text { Scrub. }\end{array}$ & 76.665 & 10 & 16 & 0,00025 \\
\hline $\begin{array}{l}\text { Scrub.-B.Filter } \\
\text { B.Filter-ID fan }\end{array}$ & 69.191 & 10 & 10 & 0,00236 \\
\hline ID fan-Stack & 67.545 & 10 & 10 & 0,00231 \\
\hline Minor losses $\left.{ }^{*}\right)$ & - & - & - & 0,0016 \\
\hline
\end{tabular}

\begin{tabular}{lc}
\hline Total & 0,010 \\
\hline ) ditetapkan $20 \%$ &
\end{tabular}

Dari data yang dihitung tersebut di atas, maka spesifikasi ID fan dalam rangcangan ini dengan menggunakan kurva fan referensi didapatkan angka-angka, kapasitas $(\mathrm{Q})=70.000 \mathrm{cfm}$, BHP = 400, mechanical efficiency $80 \%$ serta static pressure pompa $=25$ inch $\mathrm{H}_{2} \mathrm{O}$.

\subsection{Penentuan Dimensi Cerobong}

\section{Pendekatan perhitungan}

Langkah awal perhitungan dimensi cerobong adalah dengan simulasi untuk laju volume gas yang telah diperoleh sebelumnya serta penetapan suhu rata-rata gas buang dalam cerobong serta suhu rata-rata di luar cerobong. Dengan mengasumsikan molar massa dari gas dan udara luar sama, maka hambatan gesek dan heat losses diabaikan. Adapun persamaan yang digunakan adalah $^{(15,16)}$;

$Q=C \cdot A \sqrt{2 g h \frac{T_{i}-T_{o}}{T_{i}}}$

Keterangan

$Q \quad$ : flue-gas flow-rate, $\mathrm{m}^{3} /$ detik

A : luas penampang melintang cerobong, $m^{2}$ (diasumsikan konstan)

C : : koefisien 'discharge' $(0,65-0,70)$

$g: 9,807$ percepatan gravitasional, $\mathrm{m} / \mathrm{s}^{2}$

$h \quad$ : tinggi cerobong, $m$

$T_{i} \quad$ : suhu fluegas dalam cerobong, $K$

$T_{0} \quad$ : suhu udara luar, $K$

Adapun perbedaan tekanan udara antara di dasar cerobong dengan di bagian atas cerobong yang tercipta akibat draft dapat diformulasikan sebagai berikut ${ }^{(15,16)}$.

$\Delta P=C \cdot a \cdot h\left(\frac{1}{T_{o}}-\frac{1}{T_{i}}\right)$

Keterangan

$\triangle P \quad$ : Perbedaan tekanan, $P_{a}$

C : : 0,0342

a : tekanan atmosfer, $P_{a}$

$h \quad$ : tinggi cerobong, $m$

To : suhu rerata udara luar, $K$

Ti : suhu rerata flue gas dalam cerobong, $K$

Dengan persamaan (1) dan (2) tersebut di atas dilakukan simulasi dengan menentukan beberapa ukuran diameter dan ketinggian cerobong dengan kontrol pada kecepatan gas buang dalam cerobong yang setidaknya $15 \mathrm{~m} /$ detik (harus lebih tinggi dari kecepatan angin yang 4 - 7 $\mathrm{m} /$ detik di lokasi PLTSa). Hasil simulasi ditampilkan dalam tabel 5 . 
Tabel 5. Simulasi dimensi cerobong

\begin{tabular}{ccc}
\hline $\begin{array}{c}\text { Tinggi } \\
\mathrm{H}(\mathrm{m})\end{array}$ & $\begin{array}{c}\text { Diameter } \\
\mathrm{d}(\mathrm{m})\end{array}$ & $\begin{array}{c}\text { Kecepatan gas } \\
\mathrm{V}(\mathrm{m} / \text { detik })\end{array}$ \\
\hline 40 & 2,20 & 15,63 \\
\hline 70 & 2,05 & 18,89 \\
\hline 90 & 1,90 & 20,63 \\
\hline 100 & 1,75 & 26,62 \\
\hline
\end{tabular}

Hasil simulasi memperlihatkan bahwa kecepatan gas buang dalam cerobong akan meningkat sebanding dengan menurunnya diameter, serta berbanding terbalik dengan kuadrat diameternya. Walau seluruh hasil perhitungan dimensi ini memenuhi persamaan yang ada, namun pertimbangan aspek rasionalitas dan stabilitas konstruksi maka pilihan pada dimensi cerobong berdiameter $2,05 \mathrm{~m}$ serta tinggi $70 \mathrm{~m}$ menjadi pilihan.

\section{Pendekatan model dispersi Gaussian}

Perancangan cerobong selain didasarkan pada hasil perhitungan dan regulasi juga dilakukan dengan mempertimbangkan hasil pemodelan atas perilaku sebaran polutan di atmosfer. Model yang digunakan dalam melihat dispersi konsentrasi adalah Model Gaussian atau distribusi normal yang sering didapat dari proses random. Dalam studi ini model dispersi Gaussian dilakukan sederhana hanya untuk melihat besaran konsentrasi gas pada beberapa jarak horisontal dari sumber polutan pada ketinggian 10 meter. Beberapa profil dispersi gas buang dibangun oleh Pasquill (1961) dengan persamaan Gauss ganda sebagai berikut ${ }^{(17)}$.

$C=\frac{Q}{2 \pi \mu \sigma_{y} \sigma_{z}} \exp \left(-\frac{1}{2} \frac{y^{2}}{\sigma_{y}^{2}}\right)\left\{\exp \left(-\frac{1(z-H)^{2}}{2}\right)+\exp \left(-\frac{1(z+H)^{2}}{2} \frac{\sigma_{z}^{2}}{\sigma_{z}^{2}}\right)\right\}$.

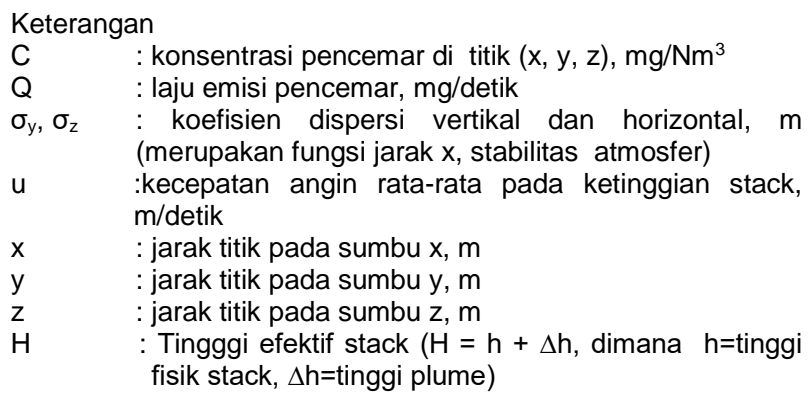

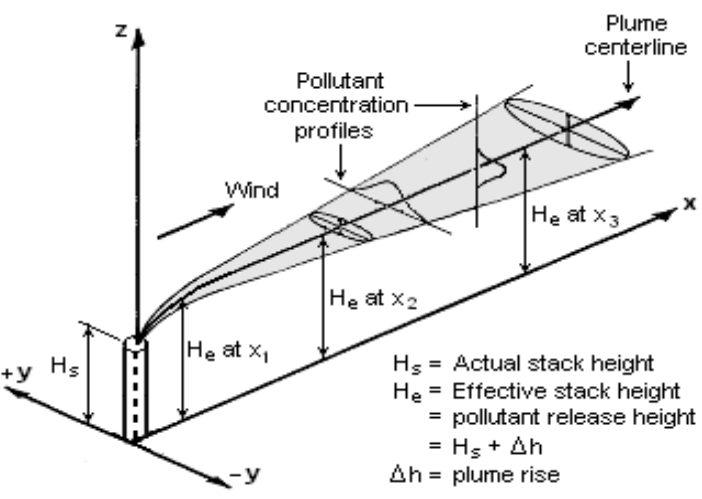

Gambar 2. Model dispersi Gaussian

Data yang digunakan dalam analisis sebaran antara lain, dimensi cerobong $(\mathrm{h}=70 \mathrm{~m}$, diameter $=$ $2,05 \mathrm{~m})$, kecepatan gas dalam stack ( $\mathrm{V}=18,89$ $\mathrm{m} /$ detik) sedang pencemar yang diuji adalah partikulat dengan konsentrasi $500 \mathrm{mg} / \mathrm{dtk}, 750$ $\mathrm{mg} / \mathrm{dtk}$ dan $1000 \mathrm{mg} / \mathrm{dtk}$. Adapun parameter meteorologis didasarkan pada data BMKG Tangerang pada bulan Februari 2018 dengan stabilitas udara kelas A (very unstable), B (moderately unstable), C (slightly unstable) dan D (netral), kecepatan angin pada ketinggian $10 \mathrm{~m}\left(\mathrm{u}_{10}\right.$ $=5 \mathrm{~m} /$ detik) dari arah timur. Pemilihan stabilitas kelas $\mathrm{A}, \mathrm{B}, \mathrm{C}$ dan $\mathrm{D}$ menunjukkan simulasi dispersi diterapkan pada kondisi siang hari. Kecepatan angin $(u)$ pada ketinggian cerobong efektif $(H)$ digunakan persamaan ${ }^{(9,18)}$;

$U=U_{10}\left(\frac{H}{10}\right)^{p}$

Keterangan

$U \quad$ : kecepatan angin di puncak stack. $m /$ detik

$U_{10} \quad$ : kecepatan angin pada level $10 \mathrm{~m}, \mathrm{~m} /$ detik

$H \quad$ : tinggi stack efektif, $m$

Nilai eksponen $(p)$ bergantung atas kelas stabilitas atmosfer. Adapun tinggi plume sangat bergantung pada momentum dan buoyancy dari fluks gas buang. Dalam studi ini perhitungan tinggi plume digunakan persamaan Holland yang telah diekstrapolasi untuk semua kelas stabilitas atmosfer (17,20);

$\Delta h=\left(4,21 \frac{V_{s} d}{U}+2,92 \frac{\left(Q_{h}\right)^{\frac{1}{2}}}{U}\right)$

Keterangan

$\begin{array}{ll}\Delta \mathrm{h} & \text { : tinggi plume, } m \\ V_{s} & : \text { kecepatan keluar fluegas, } m / \text { detik } \\ D & \text { : diameter stack, } m \\ Q_{h} & \text { : laju kalori emisi, } k \text { kal/detik }\end{array}$ 
$U \quad$ : kecepatan angin rata-rata, $\mathrm{m} /$ detik

Model Gaussian digunakan untuk memperkirakan konsentrasi partikulat pada permukaan tanah sesuai arah angin. Jarak yang diuji adalah 5 hingga 10 kali tinggi cerobong serta 1 kilometer dari cerobong, yakni $350 \mathrm{~m}, 700 \mathrm{~m}$ dan 1 $\mathrm{km}$ dari sumber polutan. Hal ini juga diverifikasi terhadap kondisi lapangan dimana permukiman terdekat dari lokasi PLTSa adalah 300 - 700 meter. Tabel 5 merupakan data dasar yang dipergunakan dalam uji simulasi model Gaussian termasuk penggunaan persamaan (4) dan $\begin{array}{llll}\text { persamaan } & \text { (5). Sedangkan Tabel } 6\end{array}$ memperlihatkan hasil simulasi Gaussian dengan menggunakan persamaan (3).

Tabel 6. Variabel dan besaran uji model

\begin{tabular}{ll}
\hline \multicolumn{1}{c}{ Variabel } & \multicolumn{1}{c}{ Besaran } \\
\hline \multirow{2}{*}{ Laju emisi partikulat } & $\mathrm{Q}_{1}=500 \mathrm{mg} / \mathrm{dtk}$ \\
\cline { 2 - 2 } & $\mathrm{Q}_{2}=750 \mathrm{mg} / \mathrm{dtk}$ \\
\cline { 2 - 2 } $\begin{array}{l}\text { Tinggi fisik stack } \\
\text { Tinggi plume }\end{array}$ & $\mathrm{h}=1000 \mathrm{mg} / \mathrm{dtk}$ \\
\hline \multirow{3}{*}{ Koefisien dispersi vertikal } & $\Delta \mathrm{h}=116,8 \mathrm{~m}$ \\
\hline \multirow{3}{*}{ Koefisien dispersi horisontal } & $\sigma_{y(1)}=25 \mathrm{~m}$ \\
\cline { 2 - 2 } & $\sigma_{y(2)}=50 \mathrm{~m}$ \\
\cline { 2 - 2 } & $\sigma_{y(3)}=70 \mathrm{~m}$ \\
\hline Kecepatan angin atas stack & $\sigma_{z(1)}=15 \mathrm{~m}$ \\
\hline Kecepatan aliran gas & $\sigma_{z(2)}=25 \mathrm{~m}$ \\
\hline & $\sigma_{z=8,133 \mathrm{~m} / \mathrm{s}}=30 \mathrm{~m}$ \\
\hline
\end{tabular}

Tabel 7. Konsentrasi polutan terhadap jarak

\begin{tabular}{ccccc}
\hline Kelas & & \multicolumn{3}{c}{$\mathrm{C}\left(\mathrm{mg} / \mathrm{m}^{3}\right)$} \\
\cline { 3 - 5 } Stabiltas & Laju & $\mathrm{x}:$ & $\mathrm{x}$ & $\mathrm{x}$ \\
& $\mathrm{emisi}$ & $350 \mathrm{~m}$ & $750 \mathrm{~m}$ & $1 \mathrm{~km}$ \\
\hline \multirow{3}{*}{$\mathrm{A}$} & $\mathrm{Q}_{1}$ & 65,1 & 64,5 & 61,3 \\
\cline { 2 - 5 } & $\mathrm{Q}_{2}$ & 83,3 & 73,5 & 71,4 \\
\cline { 2 - 5 } & $\mathrm{Q}_{3}$ & 97,4 & 82,6 & 76,5 \\
\hline \multirow{3}{*}{$\mathrm{B}$} & $\mathrm{Q}_{1}$ & 54,5 & 45,7 & 43,6 \\
\cline { 2 - 5 } & $\mathrm{Q}_{2}$ & 63,6 & 61,8 & 48,7 \\
\cline { 2 - 5 } & $\mathrm{Q}_{3}$ & 72,7 & 71,9 & 54,8 \\
\hline \multirow{3}{*}{$\mathrm{C}$} & $\mathrm{Q}_{1}$ & 39,6 & 34,3 & 33,9 \\
\cline { 2 - 5 } & $\mathrm{Q}_{2}$ & 55,5 & 51,4 & 32,0 \\
\hline & $\mathrm{Q}_{3}$ & 69,7 & 56,2 & 31,2 \\
\hline \multirow{3}{*}{$\mathrm{D}$} & $\mathrm{Q}_{1}$ & 34,8 & 20,7 & 14,4 \\
\cline { 2 - 5 } & $\mathrm{Q}_{2}$ & 51,2 & 38,7 & 21,6 \\
\cline { 2 - 5 } & $\mathrm{Q}_{3}$ & 68,4 & 50,7 & 28,7
\end{tabular}

Dari hasil simulasi pada Tabel 6 terlihat pada semua jarak serta pada laju partikulat $Q_{1}=500$ $\mathrm{mg} / \mathrm{dtk}, \mathrm{Q}_{2}=750 \mathrm{mg} / \mathrm{dtk}$ dan $\mathrm{Q}_{2}=1000 \mathrm{mg} / \mathrm{dtk}$, konsentrasi partikulat berada di bawah BME 120 $\mathrm{mg} / \mathrm{Nm}^{3}$. Konsentrasi tertinggi didapati pada jarak $350 \mathrm{~m}$, laju partikulat $1000 \mathrm{mg} / \mathrm{dtk}$ dengan kelas stabilitas atmosfer A, yakni sebesar $97,4 \mathrm{mg} / \mathrm{m}^{3}$. Stabilitas atmosfer mempengaruhi tingkat konsentrasi polutan pada suatu titik tinjau, stabilitas A akan menyebabkan konsentrasi polutan yang lebih tinggi dibanding $B, C$ maupun $D$.

\section{Pendekatan Peraturan}

Regulasi yang dirujuk dalam perancangan cerobong adalah Lampiran III dalam Keputusan Kepala BAPEDAL no: KEP-205/Bapedal/07/1996 tanggal 10 Juli 1996 tentang Pedoman Teknis Pengendalian Udara Sumber Tidak Bergerak. Dalam peraturan tersebut persyaratan perencanaan cerobong secara umum seperti berikut:

1. Tinggi cerobong sebaiknya $2-2,5$ kali tinggi bangunan sekitarnya sehingga lingkungan sekitarnya tidak terkena turbulensi.

2. Kecepatan aliran gas dari cerobong sebaiknya lebih besar dari $20 \mathrm{~m} /$ detik sehingga gas-gas yang keluar dari cerobong akan terhindar dari turbulensi.

3. Gas-gas dari cerobong dengan diameter lebih kecil dari 5 feet dan tinggi kurang dari 200 feet akan mengakibatkan konsentrasi di bagian bawah akan menjadi tinggi.

4. Konsentrasi maksimum bagian permukaan tanah dari cerobong gas-gas (agar terjadi difusi) biasanya terjadi pada jarak 5 - 10 kali tinggi cerobong downwind.

5. Konsentrasi maksimum zat pencemar berkisar antara 0,001 - 1\% dari konsentrasi zat pencemar dalam cerobong.

6. Konsentrasi di permukaan dapat dikurangi dengan menggunakan cerobong yang tinggi. Variasi konsentrasi pencemar pada permukaan akan berbanding terbalik dengan kuadrat tinggi cerobong efektif.

7. Warna cerobong harus mencolok sehingga mudah terlihat.

8. Cerobong dilengkapi dengan pelat penahan angin yang melingkari cerobong secara memanjang ke arah ujung atas.

9. Puncak cerobong sebaiknya terbuka, jika pihak industri menganggap perlu untuk memberi penutup (biasanya cerobong kecil/rendah) maka penutup berbentuk segitiga terbalik (terbuka ke atas).

10. Setiap cerobong diberi nomor dan dicantumkan dalam denah industri.

11. Disamping itu di sekitar cerobong sebaiknya dilengkapi dengan tempat parkir sehingga kendaraan sampling dapat sedekat mungkin dengan lubang sampling. Apabila cerobong tidak sesuai dengan ketentuan di atas (untuk industri yang beroperasi sebelum dan sejak tahun 1995), maka perlu dilakukan modifikasi perlakuan gas buang. Hal tersebut dilakukan 
dengan mengubah kecepatan serta temperatur gas, sehingga akan diperoleh tinggi cerobong efektif yang lebih tinggi.

Berdasar hasil perhitungan untuk perancangan didapatkan dimensi cerobong dengan diameter 2,05 m dan tinggi $70 \mathrm{~m}$. Ukuran ini masih di atas yang dipersyaratkan agar konsentrasi polutan tidak besar di bagian bawah yakni diameter kurang dari 5 kaki dan tinggi kurang dari 200 kaki. Dimensi hasil perhitungan tersebut jika dilakukan uji simulasi model Gaussian dengan varian laju volume polutan ternyata hasilnya semua di bawah BME yang dipersyaratkan baik pada jarak $350 \mathrm{~m}$, $750 \mathrm{~m}$ dan $1 \mathrm{~km}$. Penentuan jarak uji didasarkan pada ketentuan SK Ka.Bapedal no.205/1996 bahwa konsentrasi maksmum umumnya terjadi pada jarak 5-10 kali tinggi cerobong downwind.

Selain itu dalam regulasi tersebut juga dipersyaratkan tinggi cerobong sebaiknya $2-2,5$ kali tinggi bangunan sekitarnya. Di lokasi PLTSa Cipeucang, bangunan pada jarak $1 \mathrm{~km}$ dari titik lokasi cerobong paling tinggi adalah 3 lantai, sehingga ketinggian 70 dianggap memenuhi syarat. Selain itu dari sisi konsentrasi pencemar tertinggi pada jarak $350 \mathrm{~m}$ adalah $9,74 \mu \mathrm{g} / \mathrm{m}^{3}$ atau hanya $0,0009 \%$ dari konsentrasi pencemar dalam cerobong, dalam regulasi Kepala Bapedal dipersyaratkan maksimum $0,001-1 \%$ dari konsentrasi pencemar dalam cerobong..Penetapan dimensi cerobong dalam studi ini didasarkan pada kesimpulan dari ketiga pendekatan tersebut yakni perhitungan, model Gaussian dan regulasi yang ada.

\section{KESIMPULAN}

Berdasar hasil studi ini dapat diambil beberapa kesimpulan sebagai berikut;

1. Pembangunan unit PLTSa harus dilengkapi dengan peralatan pengendalian gas pencemar agar memenuhi BME, dengan cerobong sebagai ujung akhir pembuangan harus dirancang secara tepat.

2. Perancangan PLTSa kapasitas 350 ton sampah per hari menghasilkan laju gas buang 84.723 $\mathrm{kg} / \mathrm{jam}$ yang akan diolah melalui unit cyclone, semi dry scrubber, bag filter serta chimney (cerobong).

3. Perancangan dimensi cerobong dan ID fan sebagai pendorong laju gas buang ke atmosfer harus didasarkan pada hasil perhitungan, simulasi model dispersi serta peraturan yang berlaku.

4. Berdasar hasil perhitungan, uji model dispersi dan akomodasi peraturan, dalam rancangan ini ditetapkan diameter cerobong 2,05 m dengan tinggi $70 \mathrm{~m}$, serta diperlukan ID fan sebagai pendorong flue gas dengan spesifikasi $Q=$ $70.000 \mathrm{cfm}, \mathrm{BHP}=400$, mechanical efficiency $80 \%$ dan static pressure pompa $=25$ inch $\mathrm{H}_{2} \mathrm{O}$

\section{PERSANTUNAN}

Ucapan terima kasih kami sampaikan kepada Dinas Lingkungan Hidup dan Kehutanan Kota Tangerang Selatan atas dukungan informasi dan data dalam perancangan PLTSa skala pilot yang sangat bermanfaat dalam penyusunan tulisan ini.

\section{DAFTAR PUSTAKA}

1. Purwanta, W. 2017. Kajian Kebutuhan Kualitas Dan Kuantitas Air Pada Unit Pengolah Sampah Proses Termal (Waste to Energy Incinerator). Jurnal Hidrosfir Indonesia, Vol.13 No.2, p 91-98.

2. McDougall, F.R, P.R. White, M. Franke, \& P.Hindle. 2001. Integrated Solid Waste Management: a Life Cycle Inventory, Black Well Science Publishing, Oxford, UK.

3. Damanhuri, E., \& Tri Padmi. 2016. Pengelolaan Sampah Terpadu. Penerbit ITB. Bandung.

4. Martin, E.J. \& J.H. Johnson. 1987. Hazardous Waste Management. Van Nostrand Reinhold, New York.

5. European Commission. 2006. Reference Document on the Best Available Techniques for Waste Incineration

6. Niessen, W. R. 2002. Combustiop and Incineration Processes. Marcel-Dekker, Inc. New York

7. Mahanta, P. 2017. Energy Conservation and Waste Heat Recovery. Indian Institute of Technology, Guwahati, India

8. World Bank. 1999. Technical Guidance Report, Municipal Solid Waste Incineration, Washington, D.C. 20433, U.S.A.

9. Cooper, C., D., \& F.C. Alley. 1986. Air Pollution Control: A Design Approach. PWS Engineering, Boston.

10.Teir, S., \& Antto Kulla. 2002. Boiler Calculations. Helsinki University of Technology Department of Mechanical Engineering Energy Engineering and Environmental Protection Publications

11.Adel, A., \& Abdel-Rahman. 2008. On The Atmospheric Dispersion and Gaussian Plume Model. 2nd International Conference on Waste Management, Water Pollution, Air Pollution, 
Indoor Climate (WWAl'08), Corfu, Greece, October 26-28, 2008

12. Dinas Lingkungan Hidup Tangsel. 2015. Kajian kelayakan pengelolaan sampah terintegrasi di kota Tangerang Selatan - Laporan Akhir

13.Kikkawa, $H_{\text {., }} H$. Ishizaka, K. Kai, \& $T$. Nakamoto. 2008. DeNOx, DeSOx, and CO2 Removal Technology for Power Plant. Hitachi Review. Vol 57, No.5.

14.Turner, J.H., \& A. S. Viner. 2017. Sizing and Costing of Fabric Filters. Air and Waste Management Association.

15. Bureau of Energy Efficiency (BEE), Government of India. Energy Efficiency Guide Book, Chapter 5, p 93-112. 2004.

16.Sherlock, R.H. \& E.J. Lesher. 2017. Role of Chimney Design in Dispersion of Waste Gases. Journal of the Air \& Waste Management Association. Vol.4 no. 2, Agustus 1954.

17.Carson, J. E., \& Harry Moses. 1969. The Validity of Several Plume Rise Formulas. Journal of Air Pollution, 19:11, 862-866.
18. Liandy, M.K.G., E. Suswantoro, \& H. Yulinawati. 2015. Analisis Sebaran Total Suspended Particulate (TSP), Sulfur Dioksida $\left(\mathrm{NO}_{2}\right)$, Dan Nitrogen Dioksida $\left(\mathrm{NO}_{2}\right)$ di Udara Ambien Dari Emisi Pembangkit Listrik Tenaga Uap (PLTU) Banten 3 Lontar Denagn Model Gaussian. Jurnal Teknik Lingkungan. Vol.7 No.2 Des 2015, 47-56.

19. Awasthi, S., M. Khare, \& P. Gargava. 2006. General plume dispersion model (GPDM) for point source emission. Environmental Modeling and Assessment (2006) 11: 267-276.

20.Bassiouny, M. K., A. A. Hussien, \& Mostafa El Shafie. 2014. Calculations of Temperature Decay for Industrial Chimney by Using Modified Analytical Model. Journal of Mechanical and Civil Engineering (IOSRJMCE), Vol. 11, Issue 1, Jan. 2014, PP 13-24. 
